\title{
COMPARISON OF OXIDATIVE STRESS MARKERS AND ANTI-OXIDANT DEFENSE SYSTEM IN ASTHAMATIC AND NON-ASTHAMATIC WOMEN DURING SECOND TRIMESTER OF PREGNANCY
}

\author{
Faezah Siddiqui $^{\circledR}$, Ali Awais Malik ${ }^{2}$
}

\begin{abstract}
OBJECTIVE: To compare the levels of stress markers and anti-oxidants during the second trimester of pregnancy in healthy and asthmatic women.

METHODS: This cross-sectional research, conducted at Institute of Molecular Biology and Biotechnology, University of Lahore and Pak Red Crescent Teaching Hospital, Dina Nath, from October 2016 to March 2017. One hundred females ( 50 healthy and 50 asthmatics) of same age group (20-35 years) and duration of pregnancy (second trimester) were included through purposive sampling technique. Oxidative stress markers [Melanodialdehyde (MDA) and Nitric Oxide (NO)], enzymatic [Superoxide Dismutase (SOD), Catalase (CAT), Glutathione Reductase (GSH) and Glutathione Peroxidase (GPx)] and non-enzymatic (vitamin $\mathrm{E}$, vitamin $\mathrm{C}$ and vitamin $\mathrm{A}$ ) anti-oxidants were recorded.
\end{abstract}

RESULTS: Mean BMI was $21.55 \pm 0.35 \mathrm{~kg} / \mathrm{m}^{2}$ and $20.32 \pm 0.25 \mathrm{~kg} / \mathrm{m}^{2}$ (pvalue $=<0.00 \mathrm{I}$ ) in healthy and asthmatics respectively. Mean hemoglobin values were $12.2 \mathrm{I} \pm 0.2 \mathrm{lg} / \mathrm{dl}$ and $9.8 \pm 0.2 \mathrm{lg} / \mathrm{dl}(\mathrm{p}$-value $=<0.00 \mathrm{l})$. In oxidative stress marker means, MDA had I.52 \pm 0.75 and $2.86 \pm 1.18(\mathrm{p}$-value $=<0.00 \mathrm{I})$, while NO had I $2.59 \pm 1.9 I$ and I $4.91 \pm I .65(p$-value $=<0.00 I)$ in healthy $\&$ asthmatics respectively. In Enzymatic anti-oxidant means, SOD had $0.50 \pm 0.19$ and $0.15 \pm 0.21$ ( $p$-value $=<0.001)$, CAT had $3.86 \pm 0.59$ and $0.02 \pm 0.01$ ( $p$ value $=<0.00 \mathrm{I})$, GSH had $9.36 \pm \mathrm{I} .0 \mathrm{I}$ and $4.27 \pm \mathrm{I} .9 \mathrm{I}(\mathrm{p}$-value $=<0.00 \mathrm{I})$, while GPx had $9.48 \pm 1.01$ and $0.36 \pm 0.13$ (p-value $=<0.001$ ) in healthy \& asthmatics respectively. In non- enzymatic anti-oxidant means, vitamin $C$ showed $0.58 \pm 0.18$ and $0.38 \pm 0.09$ ( $p$-value $=<0.00 \mathrm{I})$, vitamin $E$ had $0.7 \mathrm{I} \pm 0.13$ and $0.34 \pm 0.1 \mathrm{I}$ ( $\mathrm{p}$ value $=<0.00 \mathrm{I}$ ), while vitamin $\mathrm{A}$ depicted $0.45 \pm 0.06$ and $0.35 \pm 0.1 \mathrm{l}$ ( $\mathrm{p}$ value $=<0.00 \mathrm{I})$ in the healthy \& asthmatics respectively.

CONCLUSION: Our study suggest that imbalance between reducing and oxidizing systems favors a more oxidative stress in asthmatic women than healthy controls during pregnancy.

KEYWORDS: Asthma (MeSH); Pregnancy (MeSH); Oxidative Stress (MeSH); Anti-oxidants (MeSH); Reactive Oxygen Species (MeSH).

THIS ARTICLE MAY BE CITED AS: Siddiqui F, Malik AA. Comparison of oxidative stress markers and anti-oxidant defense system in asthamatic and non-asthamatic women during second trimester of pregnancy. Khyber Med Univ J 2020; I 2(2):8I-5. DOI: I0.35845/kmuj.2020. 19646.

\section{INTRODUCTION}

A sthma is a chronic and complex inflammatory lung disease affecting 334 million people worldwide.' In accordance with the etiopathogenesis model of asthma, interactions between various cell types and mediators lead to airway reactivity and airflow limitation. ${ }^{2}$
Asthma and other airway diseases are diagnosed in the light of clinical features, pulmonary function tests and response to treatment. However, a recent interest in identifying and measuring inflammatory markers is expected to provide further insight in the phenotypes, prognosis and therapeutic response of asthma.
I. Pak Red Crescent Medical and Dental College, Dina Nath, Kasur, Pakistan

2. Sharif Medical and Dental College, Sharif Medical City, Jati Umrah, Lahore, Pakistan. Email『: faeexahsiddiqui8@gmail.com Contact \#: +92-333-4793656

$\begin{array}{ll}\text { Date Submitted: } & \text { August 27, 2019 } \\ \text { Date Revised: } & \text { March 30, } 2020 \\ \text { Date Accepted: } & \text { April 04, 2020 }\end{array}$

Oxidative stress occurs throughout the body whenever there is a disparity between reactive oxygen species (ROS) and ability of antioxidant defense systems to arrest oxidative damage. ${ }^{4}$ This increase in oxidative stress leads to further worsening of chronic and inflammatory conditions, including asthma. Oxidative stress is also observed in normal pregnancy. ${ }^{5}$ Due to increase in oxygen intake and energy utilization by both mother and fetus, lipid peroxide and several free radicals in the placenta causes worsening of oxidative stress. ${ }^{6}$ Melanodialdehyde (MDA) is a highly reactive carbon formed as a result of lipid peroxidation in oxidative stress. As the pregnancy progresses, oxidative stress leads to further activation of various inflammatory pathways. Nitric oxide (NO) is a gaseous biomolecule synthesized by cells during inflammation. It is considered an efficient marker of oxidative-stress leading to pathogenesis of asthma. ${ }^{7}$ Normally, cellular defenses as anti-oxidants deal with these changes in pregnancy. The Superoxide Dismutase (SOD) is an important anti-oxidant enzyme. A number of researches have shown that SOD depicts both anti-oxidant and anti-inflammatory properties and is reduced in chronic conditions e.g. asthma. The critical first line defenses in respiratory epithelium are located in respiratory epithelial fluid. This fluid contains the highest concentration of Catalase (CAT) and Glutathione Reductase $(\mathrm{GSH}){ }^{8}$ But in pregnant asthmatics patients, anti-oxidant defense is already compromised which may jeopardize health of mother and fetus.'

The main function of vitamin $A$ is maintaining epithelial cellular integrity and immune function in the body. Thus, in vitamin A deficiency, goblet cells in epithelial tissues are reduced. This further leads to reduction in mucous secretion and its antimicrobial components. ${ }^{10,11}$ Vitamin $C$ is the most essential antioxidant 
TABLE I: CIRCULATING BIOCHEMICAL MARKERS IN ASTHMATICS AND CONTROL GROUPS

\begin{tabular}{|c|c|c|c|c|}
\hline \multirow{2}{*}{\multicolumn{2}{|c|}{ Variables }} & Group II & \multirow{2}{*}{$\begin{array}{c}\text { Asthmatics } \\
(n=50)\end{array}$} & \multirow{2}{*}{ P-Value } \\
\hline & & Mean \pm SD & & \\
\hline \multicolumn{2}{|c|}{ Body Mass Index $\left(\mathrm{kg} / \mathrm{m}^{2}\right)$} & $21.55 \pm 0.35$ & $20.32 \pm 0.25$ & $<0.001$ \\
\hline \multicolumn{2}{|l|}{ Hemoglobin (g/dl) } & $12.21 \pm 0.21$ & $9.8 \pm 0.21$ & $<0.001$ \\
\hline \multirow{2}{*}{ Oxidative Stress } & $\mathrm{MDA}(\eta \mathrm{M} / \mathrm{ml})$ & $1.52 \pm 0.75$ & $2.86 \pm 1.18$ & $<0.001$ \\
\hline & $\mathrm{NO}(\mu \mathrm{M} / \mathrm{L})$ & $12.59 \pm 1.91$ & $14.91 \pm 1.65$ & $<0.001$ \\
\hline \multirow{4}{*}{$\begin{array}{l}\text { Enzymatic } \\
\text { anti-oxidants }\end{array}$} & $\mathrm{SOD}(\eta \mathrm{g} / \mathrm{ml})$ & $0.50 \pm 0.19$ & $0.15 \pm 0.21$ & $<0.001$ \\
\hline & CAT $(\mu \mathrm{M} / \mathrm{mol}$ of protein $)$ & $3.86 \pm 0.59$ & $0.02 \pm 0.01$ & $<0.001$ \\
\hline & GSH (nM/ml) & $9.36 \pm 1.01$ & $4.27 \pm 1.91$ & $<0.001$ \\
\hline & $\mathrm{GPx}(\mu \mathrm{M} / \mathrm{ml})$ & $9.48 \pm 1.01$ & $0.36 \pm 0.13$ & $<0.001$ \\
\hline \multirow{3}{*}{$\begin{array}{l}\text { Non- enzymatic } \\
\text { anti-oxidants }\end{array}$} & Vitamin $C(\mu \mathrm{g} / \mathrm{ml})$ & $0.58 \pm 0.18$ & $0.38 \pm 0.09$ & $<0.001$ \\
\hline & Vitamin $E(\mu \mathrm{g} / \mathrm{ml})$ & $0.71 \pm 0.13$ & $0.34 \pm 0.11$ & $<0.001$ \\
\hline & Vitamin $A(\mu \mathrm{g} / \mathrm{ml})$ & $0.45 \pm 0.06$ & $0.35 \pm 0.11$ & $<0.001$ \\
\hline
\end{tabular}

SOD $=$ Superoxide Dismutase, $M D A=$ Melanodialdehyde, $N \mathrm{NO}=$ Nitric Oxide, $\mathrm{CAT}=$ Catalase, $\mathrm{GSH}=$ Glutathione Reductase, $G \mathrm{Px}=$ Glutathione Peroxidase

within the lung lining fluid of the airways and is a protective factor against external oxidants such as cigarette smoke and environmental pollutants. ${ }^{12}$ Vitamin $E$ is an important antioxidant in cell membrane containing tocopherol and tocotrinol. It improves T-cells and granulocytes functions. $^{12}$

A number of researches have proposed the link between asthma and oxidative stress exhibited by increased markers of oxidative damage. Yet, very few have assessed the levels of anti-oxidants and stress markers in pregnant asthmatic females. In Pakistan, asthma prevalence is $31.58 \%$, being higher in males as compared to females. ${ }^{13}$ Despite the lower prevalence of asthma, complications and mortality rates are higher in Pakistani women. To the best of our knowledge, levels of oxidative stress markers have not been measured in Pakistan. The objective of this research was to compare the levels of stress markers and anti-oxidants during the second trimester of pregnancy in asthmatics and healthy females. Moreover, in the light of these findings, strong evidence that imbalance between reducing and oxidizing systems favor a more oxidative stress in asthma will be discussed. These findings may also support further development of anti-oxidants and their beneficial effects on chronic diseases.

\section{METHODS}

This cross-sectional research was conducted at Institute of Molecular Biology and Biotechnology, University of Lahore. The samples were taken from Pak Red Crescent Teaching Hospital, Dina
Nath, which is a Non-governmental organization, providing emergency and medical services to Pakistanis throughout the country.

Approval was taken from "Advanced Studies \& Research Board" of the Pak Red Crescent Medical and Dental College and Institute of Molecular Biology and Biotechnology, University of Lahore. During the period, from October 2016 to March 2017, three hundred and twenty patients were registered in the Gynecology and Obstetrical outdoor. Among them, fifty-seven females met the inclusion criteria of asthma. The inclusion criteria were positive medical history of recurrent dry cough, especially at night, wheezing and rhonchus, tightening of chest and shortness of breath. ${ }^{14} \mathrm{~A}$ sample size of hundred females, fifty asthmatics and fifty healthy, at a confidence level of $95 \%$ and confidence interval of 4.9 was calculated through OpenEpi software. The two groups (healthy and asthmatics) who were of the same age (20-35 years) and duration of pregnancy (second trimester) were approached in the Gynecology and Obstetrical outdoor through purposive sampling technique. The exclusion criteria for the two groups was any history of respiratory infection in the previous 6 weeks, current tobacco use, prolonged exposure to second hand smoke at home or at work and exposure to dusty environments. A written consent in national language (Urdu) was taken from all the pregnant asthmatic females and their husbands after explaining to them the purpose of the study.

Five $\mathrm{ml}$ of venous blood samples was taken from each participant under aseptic measures. The samples were centrifuged within one hour of collection, after which the sera were separated and stored at $20^{\circ} \mathrm{C}$ until assayed. Superoxide dismutase (SOD) was measured by spectrophotometer. $^{15}$ Methodology of Ohkawa for melanodialdehyde (MDA), ${ }^{16}$ Moshage method for nitric oxide(NO), ${ }^{17}$ Aebi spectrophotometer for catalase (CAT), ${ }^{18}$ and Moron Method for glutathione reductase (GSH) and glutathione peroxidase(GPx) were applied. ${ }^{19}$

Vitamin $C$, vitamin $E$ and vitamin A were assessed through commercially available kits (Human Diagnostics).

Data was collected and analyzed through (SPSS) version 25. Descriptive statistics were applied to calculate mean and standard deviation of oxidative stress markers and anti-oxidative markers in the control and study group. A two sample ttest was used and a p-value of $<0.00$ I was taken as significant for all the analysis done in this study.

\section{RESULTS}

A total of hundred females, fifty healthy and fifty asthmatics in the second trimester of pregnancy were divided into two groups. Mean of BMI, Hemoglobin level and circulating biochemical markers of both study and control groups are given in Table I. It was observed that all the stress markers were significantly altered between the two groups $(p<0.00 \mathrm{I})$.

An important finding, oxidative stress in asthmatics in the form of MDA $(2.86 \pm 1.18)$ and NO $(14.91 \pm 1.65)$ were markedly raised as compared to the control group $(p<0.001)$. However, anti-oxidative markers enzymatic; SOD $(0.15 \pm 0.21)$, GSH $(4.27 \pm 1.91), \mathrm{GPx}$ $(0.36 \pm 0.13)$ and CAT $(0.02 \pm 0.01)$ and non-enzymatic vitamin $\mathrm{A}(0.35 \pm 0 . \mathrm{I})$, vitamin $C(0.38 \pm 0.09)$ and vitamin $E$ $(0.34 \pm 0.1 \mathrm{I})$ were decreased in study group. A graphical representation of parameters which led to augmented symptoms of asthma during pregnancy is summarized in Figure $\mathrm{I}$.

\section{DISCUSSION}

Since asthma is a chronic condition, the majority of asthmatic females already have high levels of reactive oxygen species circulating in their body. This condition 
was further complicated by pregnancy and poor diet; low in anti-oxidants. ${ }^{20}$ Our study identified a high level of oxidative stress in pregnant asthmatic females. This high level of oxidative stress was marked by raised levels of MDA in the study group (2.86 \pm 1.18$)$. Since MDA is a highly reactive carbon formed as a result of lipid peroxidation in oxidative stress, the majority of studies used MDA to characterize severe asthma., ${ }^{4,21}$ Our results are similar to a study done in Iraq to monitor the changes in the MDA level as an oxidative stress marker in asthmatic patients before and after treatment with montelukast. ${ }^{22}$ Similarly, another study implies that MDA level in bronchoalveolar lavage fluid was higher in mild to moderate asthmatic patients. ${ }^{23} \mathrm{~A}$ turkish study also reported that the mean serum level of MDA was significantly raised with increasing severity of asthmatic attack among patients grouped according to degree of severity.

The enzymatic inactivation of ROS is achieved mainly by SODs, GPx, and catalase. ${ }^{25}$ These enzymes act in a cooperative fashion. ${ }^{25,26}$ Our findings showed a low level of GSH $(4.27 \pm 1.91)$ and CAT $(0.02 \pm 0.01)$ in the study group indicating the damage done by oxidative stress. ${ }^{3}$ Another anti-oxidant present in respiratory epithelium is GPx. We also observed low levels of GPx $(0.36 \pm 0.13)$ in our study group. A number of researches have shown that SOD depicts both antioxidant and anti-inflammatory properties and is reduced in chronic conditions e.g. asthma. ${ }^{27}$ These results are similar to our findings of low SOD $(0.15 \pm 0.21)$ in the study group. Vitamin $C$ plays a role in quenching ROS to counteract the ROS effect and render them harmless. Vitamin $\mathrm{E}$, a fat soluble vitamin is one of the major antioxidants in cellular membranes where it acts by protecting polyunsaturated fatty acids against oxidation. ${ }^{28}$ Our study also revealed low levels of vitamin $C$ $(0.38 \pm 0.09)$, vitamin $E(0.34 \pm 0.1 I)$ and vitamin $A(0.35 \pm 0.1 \mathrm{I})$ in asthmatic females. These findings were consistent with other observations. ${ }^{29}$ Our study has provided strong evidence that imbalance between reducing and oxidizing systems favor a more oxidative stress in asthma ${ }^{29}$. These findings also support further development of anti-oxidants and their beneficial effects. ${ }^{30}$

Although our study has identified an interesting finding related to oxidative stress in asthmatic pregnant females, it also has few limitations which should be considered for future research. First, our study was cross-sectional and thus cannot provide information on changes in levels in individual patients. Longitudinal research designs should be used to measure the oxidative stress throughout the pregnancy. Another limitation was related to the sample size. Although our sample size was sufficient to show differences in oxidative stress markers between control group and asthmatic group, the sample size was too small to generalize to the whole Pakistani population.

A final concern was regarding the effect of asthma medications on the strength of association between oxidative stress and anti-oxidant defense system. An experimental research design can be applied to identify these effects.

A number of studies have suggested that clinical indices of the patients with asthma may not correlate with the underlying inflammatory process. ${ }^{1,9,20}$ Considering this, early identification of these biomarkers may help in identifying those at risk of severe asthma. In future studies it may be gainful to compare maternal and fetal anti-oxidants and stress markers. In addition, comparing the effects of different anti-oxidants on asthmatics can provide safer therapy options of asthma management.

\section{CONCLUSION}

Our study has provided strong evidence that imbalance between reducing and oxidizing systems favor a more oxidative stress in asthma. We identified that oxidative stress was significantly raised in pregnant asthmatics, which was marked by raised levels of MDA and NO. Also, the maternal defense system was compromised in asthmatics showing low levels of enzymatic (SOD, Catalase, GSH and GPx) and non-enzymatic (Vit E, Vit C and Vit A) anti-oxidants.

\section{REFERENCES}

I. Aziz SS, Iqbal R. Asthma as a

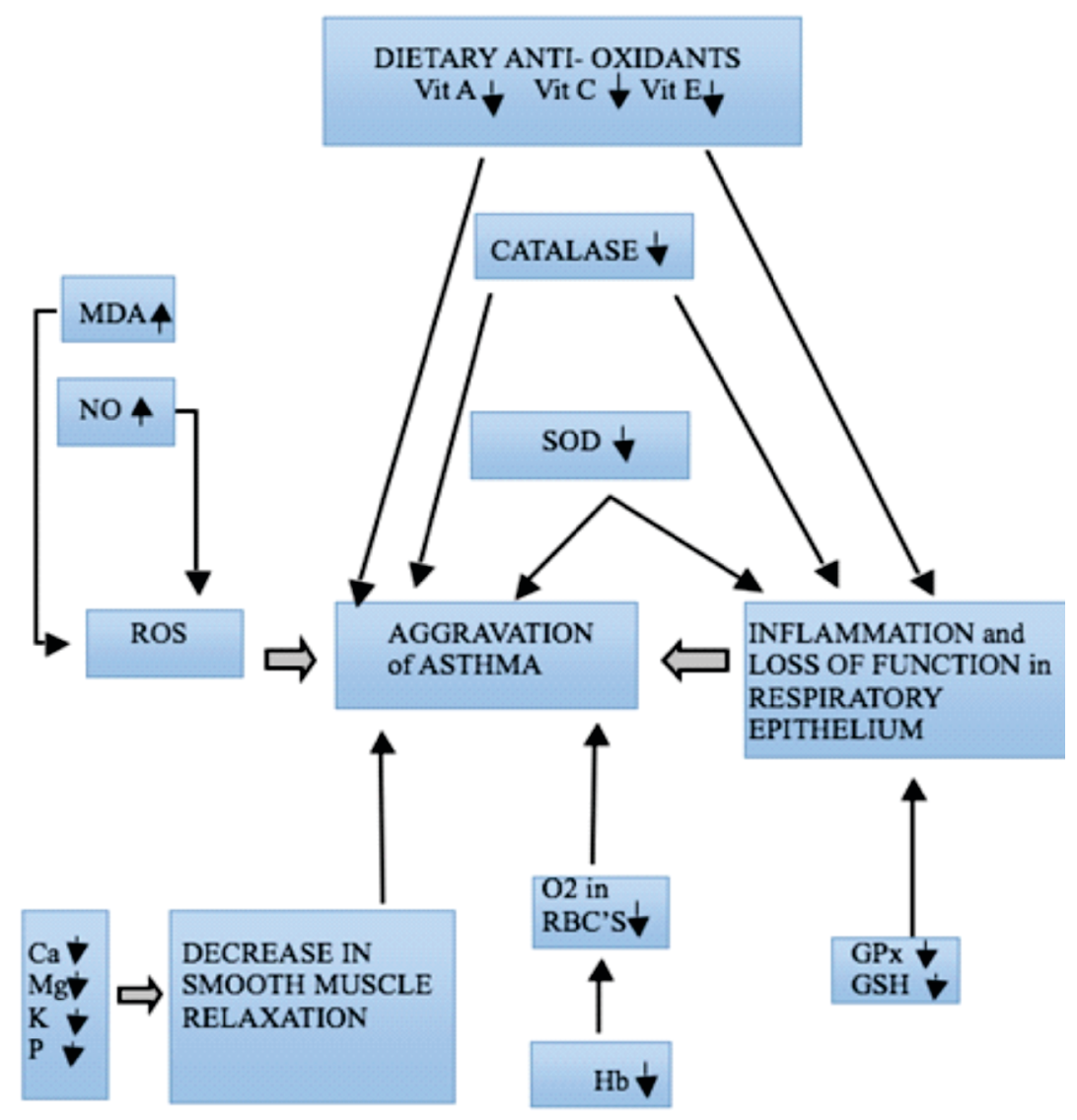

Figure I: Flowchart representing parameters involved in pregnancy and asthma 
Respiratory Disorder: A Review. Sci Inquiry Rev 2018;2(2):42-59.

2. Kostakou E, Kaniaris E, Filiou E, et al. Acute Severe Asthma in Adolescent and Adult Patients: Current Perspectives on Assessment and Management. J Clin Med 2019;8(9): |283. DOI: I0.3390/jcm809 | 283.

3. Li Y, Zhang L, Wang X, Wu W, Qin R. Effect of Syringic acid on antioxidant biomarkers and associated inflammatory markers in mice model of asthma. Drug Dev Res 2019; 80(2):253-26I. DOI: 10.1002/ddr. 21487.

4. Dozor AJ. The role of oxidative stress in the pathogenesis and treatment of asthma. Ann N Y Acad Sci 2010; I 203:133-137. DOI: 10.1 III/j. 1749-6632.2010.05562.x.

5. Awofadeju SO. Enzymatic and Nonenzymatic Biomarkers Levels in Pregnancy Trimesters in llesa South Western Nigeria. Int Blood Res Rev 2016;6(4):I-II. DOI: 10.9734/ ibrr/2016/29410

6. Bahinipati J, Mohapatra PC. Ischemia Modified Albumin as a Marker of Oxidative Stress in Normal Pregnancy. J Clin Diagn Res 2016; I0(9):BCI5-BCI7. DOI: 10.7860/ JCDR/2016/2I609.8454.

7. Whelan GJ, Silkoff PE. Noninvasive Tests, Exhaled Nitric Oxide, and Exhaled Breath Condensate - Do They Help Diagnose Asthma? In: Castro M, Kraft M. Clinical Asthma. Ist ed. Elsevier Inc:2008. pp. 97-106. [Accessed on: July 27, 2019]. Available from URL: https://www.elsevier. com/books/clinical-asthma/ 9780323042895 .

8. Riccioni G, Mancini B, Bucciarelli T, di Ilio C, D'Orazio N. Role of antioxidants in the treatment of bronchial asthma. Drug Discov Today Ther Strateg. 2006;3(3):293-8. DOI: 10.1016/j.ddstr.2006.09.010.

9. Samir D, Dalal D, Noura A. Study of Oxidative Stress during Pregnancy. Glob J Pharm Pharm Sci 2018;4(5): 555646. DOI: 10.19080/gjpps.2018. 04.555646 .

10. Bishopp A, Sathyamurthy R, Manney S, Webbster C, Krishna MT, Mansur AH. Biomarkers of oxidative stress and antioxidants in severe asthma: A Prospective Case-Control Study. Ann
Allergy Asthma Immunol. 2017;1 18 (4):445-5I. DOI: 10.10I6/j.anai. 2017.02.004.

II. Parr CL, Magnus MC, Karlstad $\varnothing$, Holvik K, Lund-Blix NA, Haugen M, et al. Vitamin $A$ and $D$ intake in pregnancy, infant supplementation, and asthma development: the Norwegian Mother and Child Cohort. Am J Clin Nutr 2018; 107(5):789-98. DOI: 10.1093/ajcn/nqy0I6.

12. McEvoy CT, Milner KF, Scherman AJ, Schilling DG, Tiller CJ, Vuylsteke B, et al. Vitamin $C$ to Decrease the Effects of Smoking in Pregnancy on Infant Lung Function (VCSIP): Rationale, design, and methods of a randomized, controlled trial of vitamin C supplementation in pregnancy for the primary prevention of effects of in utero tobacco smoke exposure on infant lung function and respiratory health. Contemp Clin Trials 2017;58:66-77. DOI: 10.1016/j. cct.2017.05.008.

13. Khan M, Ajmal MT. Prevalence of Asthma in Southern Punjab, Pakistan. Pak J Pharm Res 2016;2(I):33-6.

14. Horak F, Doberer D, Eber E, Horak E, Pohl W, Riedler J, et al. Diagnosis and management of asthma - Statement on the 2015 GINA Guidelines. Wien Klin Wochenschr 2016;128(1516):54I-54. DOI: 10.1007/s00508016-1019-4.

15. Kakkar P, Viswanathan PN. Superoxide Dismutase Isozymes and Toxicity of Environmental Xenobiotics. In: Biological Oxidation Systems. Elsevier Inc:1990. pp. 52734. [Accessed on: July 27, 2019]. Available from URL: https://www. sciencedirect.com/book/9780 I 25845 519/biological-oxidation-systems.

16. Ohkawa H, Ohishi N, Yagi K. Assay for lipid peroxides in animal tissues by thiobarbituric acid reaction. Anal Biochem 1979;95(2):35I-8. DOI: 10.1016/0003-2697(79)90738-3.

17. Moshage $H$, Kok B, Huizenga JR, Jansen PL. Nitrite and nitrate determinations in plasma: a critical evaluation. Clin Chem 1995 Jun;4I(6 Pt I):892-6.

18. Aebi H. Catalase. In: Methods of Enzymatic Analysis. New York; Verlag Chemie/Academic Press Inc: 1974. p. 673-84. DOI: 10.1016/b978-0-12-

\section{9/302-2.50032-3.}

19. Moron MS, Depierre JW, Mannervik B. Levels of glutathione, glutathione reductase and glutathione $S$ transferase activities in rat lung and liver. Biochim Biophys Acta 1979 Jan 4;582(I):67-78. DOI: 10.1016/03044I65(79)90289-7.

20. Grieger JA, Wood LG, Clifton VL. Antioxidant-rich dietary intervention for improving asthma control in pregnancies complicated by asthma: study protocol for a randomized controlled trial. Trials 2014;15:108. DOI: 10.1 186/1745-62/5-15-108.

21. Reddy PH, Hemachandra Reddy P. Mitochondrial Dysfunction and Oxidative Stress in Asthma: Implications for MitochondriaTargeted Antioxidant Therapeutics. Pharmaceuticals 201 I;4(3):429-56. DOI: $10.3390 / \mathrm{ph} 4030429$

22. Saleh JA, Suleiman SM, Zaidan ZJ Determination of MDA as oxidative stress marker and most common type of blood group in asthmatic patients before and after treatment with montelukast drug. Tikrit J Pure Sci 2018;20(2):84-7.

23. El-Alameey IR, Fathy GA, Shady MMA, Ali A, Fathy HA, Youness ER, et al. Relationship of Oxidant and Antioxidant Markers to Asthma Severity in Egyptian Asthmatic Children. Open Access Maced J Med Sci 20I7;5(5):645-50. DOI: 10.3889/ oamjms.2017.149.

24. Ozaras R, Tahan V, Turkmen S, Talay F, Besirli K, Aydin S, et al. Changes in malondialdehyde levels in bronchoalveolar fluid and serum by the treatment of asthma with inhaled steroid and beta2-agonist. Respirology 2000;5(3):289-92. DOI: 10.1046/j. I440-1843.2000.00260.x.

25. Forsberg $L$, de Faire $U$, Morgenstern R. Oxidative stress, human genetic variation, and disease. Arch Biochem Biophys 2001;389(I):84-93. DOI:I0.1006/abbi.200I.2295.

26. Masri FA, Comhair SAA, DostanicLarson I, Kaneko FT, Dweik RA, Arroliga AC, et al. Deficiency of lung antioxidants in idiopathic pulmonary arterial hypertension. ClinTransl Sci 2008; I (2):99-I06. DOI: $10.11 \mathrm{II/j}$ | 752-8062.2008.00035.x.

27. Gumral N, Caliskan S, Ozgüner F, 
Kaleli S, Akkaya A, Yilmaz $\mathrm{H}$, et al. Melatonin levels and enzymatic antioxidant defense system decrease in blood of patients with bronchial asthma. Toxicol Ind Health. 2009 Jul;25(6):4II-6. DOI: I0.II77/ 0748233709106625 .

28. Al-Abdulla NO, Al Naama LM, Hassan MK. Antioxidant status in acute asthmatic attack in children. J Pak Med Assoc 2010;60(12): 1023-7.

29. Sackesen C, Ercan H, Dizdar E, Gumus P, Tosun BN, Büyüktuncer Z, et al. A comprehensive evaluation of the enzymatic and nonenzymatic antioxidant systems in childhood asthma. J Allergy Clin Immunol 2008; I 22(I):78-85. DOI: I0. 1016/j.jaci.2008.03.035.

30. Ali Z, Nilas L, Ulrik CS. Low risk of adverse obstetrical and perinatal outcome in pregnancies complicated by asthma: A case control study. Respir Med 2016;120:124-30. DOI: 10.1016/j.rmed.2016.10.004.

\section{AUTHORS' CONTRIBUTIONS}

Following authors have made substantial contributions to the manuscript as under:

FS: Conception and study design, acquisition of data, drafting the manuscript, critical review, final approval of the version to be published.

AAM: Acquisition, analysis and interpretation of data, drafting the manuscript, final approval of the version to be published

Authors agree to be accountable for all aspects of the work in ensuring that questions related to the accuracy or integrity of any part of the work are appropriately investigated and resolved.

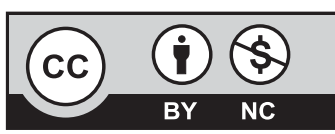

This is an Open Access article distributed under the terms of the Creative Commons Attribution-Non Commercial 2.0 Generic License.
KMUJ web address: www.kmuj.kmu.edu.pk

Email address: kmuj@kmu.edu.pk 